\title{
STUDI PEMETAAN KESESUAIAN BUDIDAYA KERANG HIJAU (Perna Viridis) MENGGUNAKAN DATA CITRA SATELIT DAN SIG DI PERAIRAN LAUT TEJAKULA
}

\author{
Wisnawa, I Gede Yudi \\ Jurusan Budidaya Kelautan, Fakultas MIPA \\ Universitas Pendidikan Ganesha \\ Singaraja, Indonesia \\ e-mail: yudiwisnawa@yahoo.co.id
}

\begin{abstract}
Abstrak
Tujuan utama dari penelitian ini adalah untuk mendapatkan lokasi dan seberapa luas lahan perairan pesisir dan laut Tejakula yang dapat dikembangkan untuk budidaya kerang hijau (Perna Viridis). Penelitian ini merupakan penelitian deskriptif kuantitatif dengan mengkompilasi data citra satelit, kemudian dianalisis dengan menggunakan Sistem Informasi Geografis untuk menjelaskan dan menggambarkan kesesuaian aspek biofisik lingkungan perairan laut di daerah penelitian terhadap budidaya kerang hijau. Hasil analisis kesesuaian perairan bagi pengembangan budidaya kerang hijau di perairan Tejakula berada pada kelas sesuai bersyarat (S3). Berdasarkan pada empat parameter biofisik (klorofil-a, substrat perairan, suhu permukaan, dan kedalaman perairan), hanya parameter substrat perairan dan kedalaman perairan yang menjadi variabel paling berpengaruh, sehingga sebaran lokasi budidaya ideal dibatasi oleh parameter substrat dan kedalaman perairan.
\end{abstract}

Kata kunci: kerang hijau (Perna Viridis), kesesuaian, budidaya, citra satelit, SIG.

\begin{abstract}
The main objective of this study was to obtain the location and extent of land and marine coastal waters Tejakula that can be developed for the cultivation of green mussel (perna viridis). This research is descriptive quantitative research by compiling satellite imagery data, and then analyzed using Geographic Information System to describe and illustrate the suitability of the biophysical aspects of the marine environment in the area of research on the cultivation of mussels. The results of the analysis of the suitability of water for cultivation of green mussels in the waters Tejakula be conditional on appropriate class (S3). Based on four biophysical parameters (chlorophyll-a, the substrate water, surface temperature, and water depth), only the parameters of the substrate and the water depth waters become the most influential variable, so that distribution is limited by the location ideal culture substrate parameters and water depth.
\end{abstract}

Keywords: green mussels (Perna Viridis), conformity, culture, satellite imagery, GIS.

\section{PENDAHULUAN}

Untuk mewujudkan kegiatan budidaya laut yang berhasil guna dan berdaya guna terutama untuk komoditas kerang hijau (Perna Viridis), maka penentuan lokasi yang sesuai dengan kondisi perairan yang diharapkan perlu menjadi perhatian. Tujuan utama dari penelitian ini adalah untuk mendapatkan lokasi dan seberapa luas lahan perairan pesisir dan laut Tejakula yang dapat dikembangkan untuk budidaya kerang hijau (Perna Viridis). Penentuan lokasi tersebut didasarkan pada parameter-parameter biofisik lingkungan, dan analisa spasial 
mengenai kesesuaian lahan di perairan laut Tejakula.

Kecamatan Tejakula merupakan salah satu kecamatan yang ada di Kabupaten Buleleng. Letak secara astronomis kecamatan Tejakula terletak pada $8^{\circ} 56^{\prime} \mathrm{LS}$ - $115^{\circ} 8^{\prime} \mathrm{BT}$. Sedangkan secara administrasi kecamatan Tejakula memiliki batas wilayah sebagai berikut:

1. Bagian utara berbatasan langsung dengan Laut Bali.

2. Bagian timur berbatasan dengan Desa Tianyar, Kecamatan Kubu, Kabupaten Karangasem.

3. Bagian selatan berbatasan dengan Desa Kutuh, Kecamatan Kintamani, Kabupaten Bangli.

4. Bagian barat berbatasan dengan Desa Bukti Kecamatan Kubutambahan.

Luas Kecamatan Tejakula adalah $97,68 \mathrm{Km}^{2}$. Keseluruhan luas kecamatan ini terbagi dalam 10 desa yang ada di Tejakula. Secara umum kondisi perairan Tejakula masih dalam kondisi baik, dengan kesuburan perairan yang relatif produktif. Penyuburan perairan Tejakula terjadi sepanjang tahun baik pada musim barat maupun pada musim timur. Pada musim barat penyuburan terjadi karena adanya run off dari daratan Tejakula yang tergolong sebagai bentuk lahan denudasional (bentuk lahan asal proses pengikisan/akibat transpor air pada lereng) dalam jumlah besar saat terjadi musim hujan, sedangkan pada musim timur terjadi penaikan massa air (upwelling) di beberapa lokasi di perairan Tejakula.

Pantai Tejakula disusun oleh batuan dari ukuran bongkahan, kerikil dan pasir berwarna kelabu sampai kehitaman. Tutupan terumbu karang yang hidup di area pemanfaatan Tejakula adalah tipe terumbu karang tepi dan gugusan-gugusan Karang atau "patches" yang tumbuh sekitar 50 sampai 100 meter dari garis pasang surut. Karang tumbuh dari dasar pasir hitam halus dan pecahan-pecahan karang di kedalaman 4 meter sampai 30 meter.

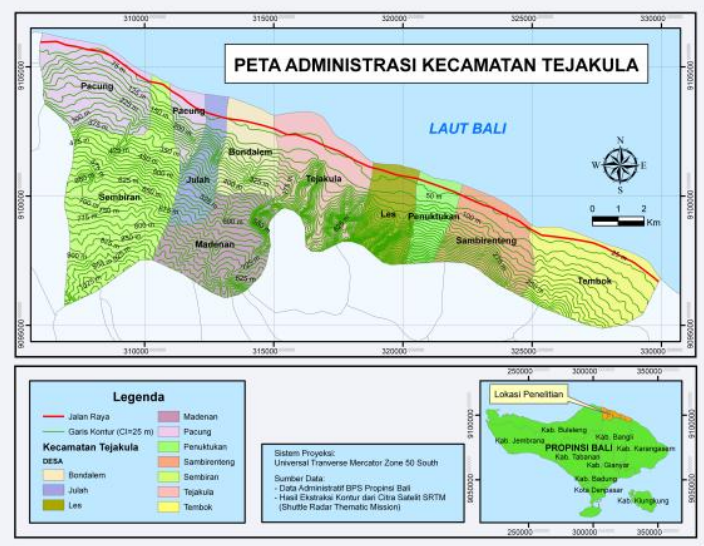

\section{METODE}

Penelitian ini dilakukan dengan mengambil lokasi pada perairan laut kecamatan Tejakula yang merupakan bagian dari perairan kawasan timur dari Kabupaten Buleleng. Batas perairan yang diamati dengan luas $312,58 \mathrm{~km}^{2}$ pada posisi lintang 07 $50^{\prime} 00^{\prime \prime}$ LS - $08^{\circ} 10^{\prime} 00^{\prime \prime}$ LS dan posisi bujur $115^{\circ} 14^{\prime} 26^{\prime \prime}$ BT - 115²7'21" BT. Penelitian ini merupakan penelitian deskriptif kuantitatif yaitu dengan mengkompilasi data citra satelit, kemudian dianalisis dengan menggunakan Sistem Informasi Geografis untuk menjelaskan dan menggambarkan kesesuaian aspek biofisik lingkungan perairan laut di daerah penelitian terhadap budidaya kerang hijau. Objek dari penelitian ini adalah aspek biofisik lingkungan perairan di Tejakula meliputi klorofil-a, substrat perairan, kedalaman perairan, dan suhu permukaan. Tipe data yang digunakan berupa data primer dan data sekunder. Data yang tergolong sebagai data primer antara lain: klorofil-a, suhu permukaan laut, substrat dasar, kedalaman perairan, penggunaan lahan. Sedangkan data yang tergolong sebagai data sekunder antara lain: jaringan jalan dan sungai, serta infrastuktur pendukung.

Proses pengolahan data ini dilakukan dengan bantuan perangkat lunak ENVI 4.4 dan ArcGIS 9.3. Untuk mendapatkan kelas kesesuaian maka dibuat matrik kesesuaian perairan untuk parameter 
fisika, kimia dan biologi. Penyusunan matrik kesesuaian perairan merupakan dasar dari analisis keruangan melalui skoring dan faktor pembobot. Hasil skoring dan pembobotan dievaluasi sehingga didapat kelas kesesuaian yang menggambarkan tingkat kecocokan dari suatu bidang untuk penggunaan tertentu.

Hasil evaluasi dari sistem penilaian kesesuaian bagi lokasi budidaya kerang hijau diklasifikasikan menjadi 4 kelas tingkat kesesuaian, diantaranya: Sangat Sesuai (S1) dengan kisaran nilai $85-100 \%$, Sesuai (S2) dengan kisaran nilai $75-84 \%$, Sesuai Bersyarat (S3) dengan kisaran nilai $51-74 \%$, dan Tidak Sesuai (N) dengan kisaran nilai $<50 \%$.

\section{HASIL DAN PEMBAHASAN \\ Pra Pemrosesan Citra \\ a. Koreksi Radiometrik}

Koreksi radiometrik tidak dilakukan lagi dalam penelitian ini, MODIS yang dipergunakan terkoreksi secara radiometrik. Mengingat citra yang digunakan telah terkoreksi radiometrik secara sistematis dan tidak dimaksudkan untuk analisis multitemporal berbasis nilai indeks maka koreksi atau kalibrasi radiometrik tidak diperlukan (Phinn, 2002 dalam Danoedoro, 2004).

\section{b. Koreksi Geometrik}

Koreksi geometrik pada citra satelit MODIS juga tidak lagi perlu dilakukan, karena citra telah terkoreksi geometrik secara sistematis berdasarkan posisi koordinat lokal yang ada. Penerapan koreksi geometrik pada citra satelit untuk kajian lautan dan dengan resolusi rendah sangatlah sulit dan berbeda daripada citra satelit untuk kajian daratan. Hal ini disebabkan pada daerah kajian lautan tentu akan lebih sulit untuk mencari area/lokasi yang tidak mengalami perubahan sebagai Ground Control Points (GCP).

\section{c. Pemotongan Citra}

Pemotongan citra dilakukan dengan mengikuti penentuan luasan blok sampel seluas $312,58 \mathrm{~km}^{2}$ yang didasarkan pada luasan vektor yang telah dibuat sebelumnya. Daerah penelitian hasil proses pemotongan citra mempunyai letak pada koordinat geografis dengan posisi lintang $07^{\circ} 50^{\prime} 00^{\prime \prime} L S$

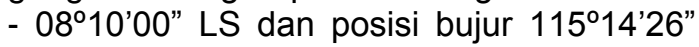
BT - $115^{\circ} 27^{\prime} 21^{\prime \prime}$ BT.

\section{Klorofil-a}

Kisaran umum kandungan klorofil-a di perairan Tejakula pada bulan Juni sampai dengan bulan Agustus (musim timur) relatif tinggi, berkisar antara $0-1 \mathrm{mg} / \mathrm{m}^{3}$. Sebaran spasial secara horisontal tampak jelas bahwa terjadi peningkatan kandungan klorofil-a yang cukup signifikan dari awal periode musim timur hingga akhir periode musim timur. Peningkatan kandungan klrofil$a$ ini cenderung terjadi pada zone lepas pantai, hal ini terjadi karena adanya penaikan massa air laut (upwelling) di beberapa lokasi di perairan Tejakula. Kuat dugaan terjadinya penaikan massa air laut di perairan Tejakula disebabkan oleh bertemunya arus permukaan dari Laut Jawa dan Laut Flores yang dipengaruhi oleh angin munson barat daya dengan arus hangat pasifik utara (north pacific thermocline) yang menyusuri Selat Makasar dan diteruskan melalui Selat Lombok. Pada awal musim timur di bulan Juni, berdasarkan hasil ekstraksi data citra MODIS terhadap kandungan klorofil-a, diperoleh nilai rerata klorofil-a sebesar $0,63 \mathrm{mg} / \mathrm{m}^{3}$ yang didominasi oleh kelas klorofil-a 0,36 - 0,75 $\mathrm{mg} / \mathrm{m}^{3}$ (Gambar 4.1). Distribusi klorofil-a secara horisontal masih belum jelas pola zonanya, hal ini diduga oleh karena pada bulan Juni merupakan awal dari periode musim timur, sehingga dampak dari sirkulasi massa air serta kondisi hidrologis perairan selama musim peralihan masih turut mempengaruhi pola distribusi di bulan ini.

\section{Suhu Permukaan Laut}

Suhu perairan juga merupakan faktor penting dalam penentuan lokasi budidaya. Berdasarkan syarat kualitas perairan untuk budidaya, suhu yang baik untuk pertumbuhan kerang hijau adalah 24 - 
$30^{\circ} \mathrm{C}$. Nilai suhu permukaan laut pada musim timur di perairan utara cenderung lebih hangat dengan rata-rata suhu antara $30-31^{\circ} \mathrm{C}$. Berdasarkan sebaran nilai suhu permukaan laut tersebut, perairan Bali Utara secara umum cukup sesuai (S2) untuk usaha budidaya kerang hijau.

Effendi (2003) mengatakan bahwa, suhu perairan berhubungan dengan kemampuan pemanasan oleh sinar matahari, waktu dalam hari dan lokasi. Hal ini didukung oleh Basmi (1999) dan Hutabarat (2000) yang mengatakan bahwa, air lebih lambat menyerap panas tetapi akan menyimpan panas lebih lama dibandingkan dengan daratan.

\section{Substrat Dasar Perairan}

Hasil penelitian terhadap material dasar perairan Tejakula memperlihatkan bahwa adanya perbedaan jenis material dasar perairan, pada beberapa lokasi. Perbedaan tersebut dapat dibagi atas tiga cluster wilayah, antara lain : a) Jenis lempung yang bercampur pasir dan debu, debu dan yang terakhir liat; b) Jenis pasir yang berada di mulut teluk; c) Jenis koral dan campuran koral pasir yang berada di depan mulut teluk.

Hasil penelitian menunjukan bahwa material dasar perairan pada perairan Tejakula masih berada dalam kisaran yang dianjurkan bagi kegiatan budidaya laut, terutama pada bagian timur dengan komposisi pasir berkarang dan karang.

\section{Kedalaman perairan}

Berdasarkan kriteria kesesuaian, batimetri yang sesuai (S1) untuk pelaksanaan budidaya kerang hijau adalah 2,5 - $5 \mathrm{~m}$, batimetri yang cukup sesuai (S2) adalah antara 5-10 m. Kedalaman yang lebih rendah dapat menyebabkan kerang mudah mengalami kekeringan dan perairan mudah keruh, sedangkan kedalaman yang terlalu dalam berakibat gelombang cenderung lebih besar dan membutuhkan tali jangkar ataupun patok yang lebih panjang.
Matrik kesesuaian bagi penentuan lokasi budidaya kerang hijau di perairan Tejakula dapat dilihat pada tabel berikut.

Total nilai skor matrik kesesuaian bagi penentuan lokasi budidaya kerang hijau di perairan Tejakula

\begin{tabular}{|l|c|}
\hline Variabel & Total Skor \\
\hline Klorofil-a $\left(\mathrm{mg} / \mathrm{m}^{3}\right)$ & 10 \\
\hline Suhu Permukaan $\left({ }^{\circ} \mathrm{C}\right)$ & 6 \\
\hline Substrat Dasar Perairan & 15 \\
\hline Kedalaman Perairan $(\mathrm{m})$ & 20 \\
\hline NILAI SKOR (\%) & $\mathbf{5 1}$ \\
\hline
\end{tabular}

Berdasarkan tabel di atas memperlihatkan nilai skor untuk budidaya kerang hijau sebesar $51 \%$. Evaluasi terhadap nilai tersebut memperlihatkan perairan Tejakula berada pada kelas sesuai bersyarat (S3) untuk budidaya kerang hijau. Analisis keruangan dari kegiatan budidaya kerang hijau di perairan Tejakula pada kelas ini mempunyai pembatas permanen, sehingga mencegah segala kemungkinan perlakuan pada daerah tersebut. Hasil indentifikasi terlihat variabel dalam variabel primer mempunyai nilai yang rendah dan sukar diberi masukan. Walaupun kondisi perairan berada pada kelas sesuai bersyarat (S3), tetapi diperlukan penjabaran mengenai variabel yang berperan didalamnya. Berikut ini adalah analisis keruangan dari kerang hijau.

Variabel kedalaman ini penting karena dianggap berkaitan dengan penetrasi cahaya dan persebaran plankton. Dengan kedalaman yang ideal, diharapkan dapat memberikan kondisi perairan yang cukup gelap akibat dari kemampuan penetrasi cahaya yang mulai berkurang. Material dasar perairan merupakan variabel yang teridentifikasi. Pembukaan dan penutupan cangkang kerang tergantung pada lama penyinaran. Agar organisme ini merasa lebih nyaman maka suasana 
pemeliharaan harus lebih gelap, dengan tujuan agar cangkang lebih terbuka dan proses filtrasi pakan dapat berjalan secara maksimal dan alami (Winanto, 2002).

Pentingnya material dasar perairan bagi kerang hijau adalah berkenaan dengan kebiasaan hidup dan sifat fisiologinnya. Daerah yang mempunyai dasar perairan terdiri dari pasir, karang dan campuran keduanya merupakan habitat yang cocok bagi kehidupan kerang. Suatu organisme akan bertumbuh dengan baik, jika berada pada habitatnya (Departemen Kelautan dan Perikanan, 2002). Hal senada juga dikatakan oleh Winanto (2005) bahwa, kerang hijau hidup pada daerah yang mempunyai substrat batu karang, rataan terumbu karang dan substrat keras lainnya. Sedangkan klorofil-a merupakan variabel tersier, yang tidak berhubungan langsung dengan kegiatan budidaya kerang hijau. klorofil-a merupakan zat hijau daun dari jasad renik di laut yang membantu proses fotosintesa.

\section{SIMPULAN}

Berdasarkan hasil dan pembahasan, maka dapat ditarik beberapa kesimpulan sebagi berikut.

1. Hasil analisis kesesuaian perairan bagi pengembangan budidaya kerang hijau di perairan Tejakula berada pada kelas sesuai bersyarat (S3).

2. Berdasarkan pada empat parameter biofisik (klorofil-a, substrat perairan, suhu permukaan, dan kedalaman perairan), hanya parameter substrat perairan dan kedalaman perairan yang menjadi variabel paling berpengaruh dalam penentuan kelayakan perairan laut untuk budidaya kerang hijau.

\section{SARAN}

Berdasarkan pada hasil yang diperoleh pada penelitian ini, dapat dikemukakan beberapa saran, antara lain sebagai berikut.

1. Mengingat kelas kesesuaian untuk budidaya kerang hijau di Tejakula berada pada taraf sesuai bersyarat, maka direkomendasikan untuk lokasi pengembangan budidaya kerang hijau hanya pada kelas sesuai bersyarat (S3.

2. Perlu dilakukan penelitian lanjutan mengenai aspek sosial- ekonomi dan aspek pencemaran lingkungan sehingga terbentuk suatu out put yang lengkap. Kemudian analisis tersebut dapat disajikan dalam bentuk spatial.

\section{DAFTAR PUSTAKA}

Basmi, J. 1999. Planktonologi (Bioekologi Plankton Algae). Fakultas Perikanan dan IImu Kelautan Institut Pertanian Bogor. Bogor.

Projo Danoedoro. 2004. Sains Informasi Geografis : Dari Perolehan dan Analisis Citra hingga Pemetaan dan Pemodelan Spasial, Yogyakarta: Jurusan Kartografi dan Penginderaan Jauh.

Departemen Kelautan dan Perikanan. 2002. Modul Sosialisasi dan Orientasi Penataan Ruang, Laut, Pesisir dan Pulau-Pulau Kecil. Ditjen Pesisir dan Pulau-Pulau Kecil. Direktorat Tata Ruang Laut, Pesisir dan PulauPulau Kecil, Jakarta.

Effendi. H. 2003. Telaah Kualitas Air bagi Pengelolaan Sumberdaya dan Lingkungan Perairan. Penerbit Kanisius, Yogyakarta.

Hutabarat, S., 2000. Produktivitas Perairan dan Plankton. Telaah Terbadap IImu Perikanan dan Kelautan. Badan penerbit Universitas Diponegoro.

Jurnal Sains dan Teknologi |243 